\title{
English comparatives as degree-phrase relative clauses
}

\author{
Richard McCoy ${ }^{*}$
}

\begin{abstract}
It has been observed (e.g. Chomsky 1977) that English questions allow wh-movement of adjective phrases, but relative clauses do not, which is cited as a notable difference between two types of constructions that are otherwise very similar. However, I argue that relative clauses actually can arise from the $w h$ movement of adjective phrases (which I here treat as degree phrases headed by a degree element) and that comparative clauses are the result; i.e., comparatives are actually relative clauses headed by degree phrases. This analysis removes the discrepancy between questions and relative clauses with regard to adjective movement, thereby further uniting the syntactic analysis of the two constructions.
\end{abstract}

Keywords. comparatives; relative clauses; wh-movement; English syntax

1. Introduction. Chomsky (1977) observes that "questions but not relatives can have whmovement of adjective phrases," a statement meant to show how questions and relatives do have some differences despite both arising from $w h$-movement. This view is supported by the sentences below:

a. The boy cried, "Wolf!"

b. Who cried, "Wolf!"?

c. I just met the boy who cried, "Wolf!"

d. I just met the boy that cried, "Wolf!"

(2) a. The pasta is delicious.

b. How is the pasta?

c. * The pizza is delicious how the pasta is.

d. * The pizza is delicious that the pasta is.

(2b) shows how questions can be formed by the wh-movement of the adjective phrase How in the same way as they can be formed by the movement of the determiner phrase Who in (1b).

However, although relative clauses can also be formed by the movement of a determiner phrase as in (1c) or (1d), the analogous process results in ungrammaticality when applied to an adjective phrase as in $(2 \mathrm{c})$ or $(2 \mathrm{~d})$.

Although the obvious modes of generating relative clauses by the movement of adjective phrases result in ungrammaticality, comparatives can actually be viewed as relative clauses resulting from the $w h$-movement of adjective phrases. For example, the ungrammatical sentences in (2c) and $(2 \mathrm{~d})$ can be put into grammatical form by becoming the comparative in (3):

(3) The pizza is as delicious as the pasta is.

Evidence for the treatment of such comparatives as relative clauses comes from the fact that the comparatives, like restrictive relative clauses, arise from $w h$-movement and in particular result from a form of raising parallel to the promotion analysis of relative clauses proposed by Kayne

\footnotetext{
${ }^{*}$ I would like to thank Bob Frank and Raffaella Zanuttini for offering comments on the analysis. Any errors of course remain my own. Author: Richard McCoy, Yale University (richard.mccoy@yale.edu).
} 
(1994) (as a modification of the structure of Vergnaud (1974)). Based on an analysis of comparatives as focusing on the degrees of the adjectives involved, the usage of a projection called DegP (degree phrase) makes the parallel between relative clauses and comparatives more explicit. With a structure similar to that of a DP, DegP is headed by a degree marker such as more or as and contains the adjective phrase as a complement following Abney (1987). Further support for the relative clause analysis comes from the fact that, in some dialects, as may be used as to introduce a relative clause.

2. Relatives and comparatives as instances of $\boldsymbol{w h}$-movement. It is long-established that both comparatives and relative clauses may be considered as instances of $w h$-movement (e.g. Chomsky 1977). The following sentences provide some of the evidence that relative clauses arise from wh-movement:

(4) I saw the $\operatorname{man}_{i}$ who you said that Mary thinks that John believes that I knew $t_{i}$ in high school.

(5) a. ${ }^{*}$ This is the book $_{i}$ that I can't remember who wrote $t_{i}$.

b. ${ }^{*}$ This is the candidate ${ }_{i}$ who I support the view that the nation should elect $t_{i}$.

(6) a. I met the $\operatorname{woman}_{i}$ who $_{i}$ she $_{j}$ hopes the nation will elect $t_{i}$.

b. * I met the $\operatorname{woman}_{i}$ who $_{i}$ she $_{i}$ hopes the nation will elect $t_{i}$.

(7) a. John found the book $_{i}$ that you said $t_{i}$ was lost.

b. * John found the book $_{i}$ that you said that $t_{i}$ was lost.

(4) shows the unboundedness of the movement in forming relative clauses; (5a) and (5b) show the sensitivity of this construction to some of the islands discussed by Ross (1967) (in these cases, complex noun phrases and wh-islands); (6a) and (6b) show the strong crossover effects of relativization; and (7a) and (7b) illustrate how comp-trace effects are also observed. Thus, because the formation of relative clauses displays these four major characteristics of $w h$ movement, it is likely to be the result of such movement.

Because strong crossover effects and comp-trace effects only apply to the movement of DPs and subjects of clauses, neither of these effects are observed for comparatives, which I analyze as involving the movement of adjective phrases, which are not DPs and which generally do not form the subjects of clauses. Although there is no convenient way to test comparatives for strong crossover effects and comp-trace effects, they do still display two major traits of wh-movement, namely unboundedness and sensitivity to islands. (8) illustrates the unboundedness of the movement resulting in comparatives, and (9a), (9b), (9c), (9d), and (9e) show sensitivity to the Complex NP Constraint, the $W h$-island Constraint, the Sentential Subject Constraint, the Coordinate Structure Constraint, and the Adjunct Island Condition respectively ((9a) and (9b) are taken from Chomsky (1977)):

(8) I am as happy $i$ as Fred said Mary thought John is $t_{i}$.

(9) a. * Mary isn't the same ${ }_{i}$ as John believes Bill's claim that she was $t_{i}$ five years ago.

b. * Mary isn't the same ${ }_{i}$ as I wonder whether she was $t_{i}$ five years ago.

c. * Mary isn't as tall $l_{i}$ as that John is $t_{i}$ surprised me.

d. * Mary isn't as tall $i$ as John is $t_{i}$ and skinny.

e. ${ }^{*}$ This movie was not as frightening ${ }_{i}$ as John screamed because your movie was $t_{i}$.

Therefore, as Chomsky (1977) argues, comparatives (like relatives) can indeed be seen as a type of wh-movement. 
3. The raising analysis of relative clauses. Even once relatives and comparatives have been established to be instances of wh-movement, other aspects of their derivation remain to be specified. Vergnaud (1974) fleshes out the structure of relative clauses by arguing that the heads of restrictive relative clauses originate inside the relative clause and then move out to become the head of the relative clause. The main arguments for this stance derive from analyses of idiom chunks (as in (10)) and the binding theory as seen with reconstruction effects (as in (11)):

(10) Mary approves of the significant headway ${ }_{i}$ that John made $t_{i}$.

(11) Mary saw the [pictures of [each other $\left.]_{j}\right]_{i}$ which they $y_{j}$ found $t_{i}$ yesterday.

Because headway only occurs in English when selected for by make, headway in (10) must have originated as a complement of make and then must have moved out of the relative clause to yield the surface structure. Furthermore, the anaphor each other would be ungrammatical by Principle A of the binding theory if it originated in its current position because it is not bound, but if each other were to start where its trace is marked, it would then be bound in its domain in that position, thereby satisfying the binding theory. Thus, it is likely that relative clauses involve the raising of the head DP from within the relative clause.

4. Binding evidence for the raising analysis of comparatives. Binding arguments can also be used to posit a similar type of raising-based derivation for comparatives. Consider the following sentences:

(12) * We're not half as [proud of him $]_{i}$ as $\mathrm{John}_{j}$ is $t_{i}$.

(13) We're not half as [proud of $\left.\operatorname{him}_{j}\right]_{i}$ as his hife $_{j}$ is $t_{i}$.

The surface structure of sentence (12) does not in any way violate binding theory because neither the pronoun him nor the R-expression John is bound. However, if proud of him were to originate inside the relative clause at the position marked $t_{j}$, then him would be bound in its domain by John, violating Principle B of the binding theory, which would explain the sentence's ungrammaticality. (13), by contrast, is grammatical because his, being only a left-branch of the larger DP his wife, does not c-command $t_{j}$. Therefore, in (13), him is not bound in its domain, thereby satisfying Principle B of the binding theory. These facts support the conclusion that comparatives are derived from a process of adjective raising parallel to the promotion analysis proposed by Vergnaud (1974) and expanded upon by Kayne (1994).

5. DegP. It is conventional to state that comparatives relate degrees across constituents (e.g. Bresnan 1973, Kennedy 1997, Lechner 1998). Like Kennedy (1997) and Lechner (1998), I take adjective phrases to actually be degree phrases headed by degree markers such as -er, as, or how, following Abney (1987). This approach solves a major issue with using Kayne's (1994) relative clause analysis to deal with comparatives as this approach has been described so far. Consider (14) below as an example of a relative clause structured under this interpretation: 
(14)



In this structure, book, the head of the relative clause, appears inside the CP, but the head of the overall DP appears outside the CP. If we do not treat adjective phrases as actually being degree phrases, this is problematic for the analysis of comparatives as relative clauses because we would need a single adjective acting as both the head of the relative clause and the head of the AP that contains the relative clause. However, it would be impossible for this single constituent to appear both inside and outside of the CP.

Incorporating the DegP analysis solves this problem. As discussed in Abney (1987), a DegP and an AP would hold the same relationship as a DP and NP share, as shown in the trees below:


Using this DegP structure, the comparative sentence in (17) can easily be assimilated to Kayne's (1994) relative clause structure with the tree in (18):

(17) The pizza is as delicious as the pasta is. 
(18)

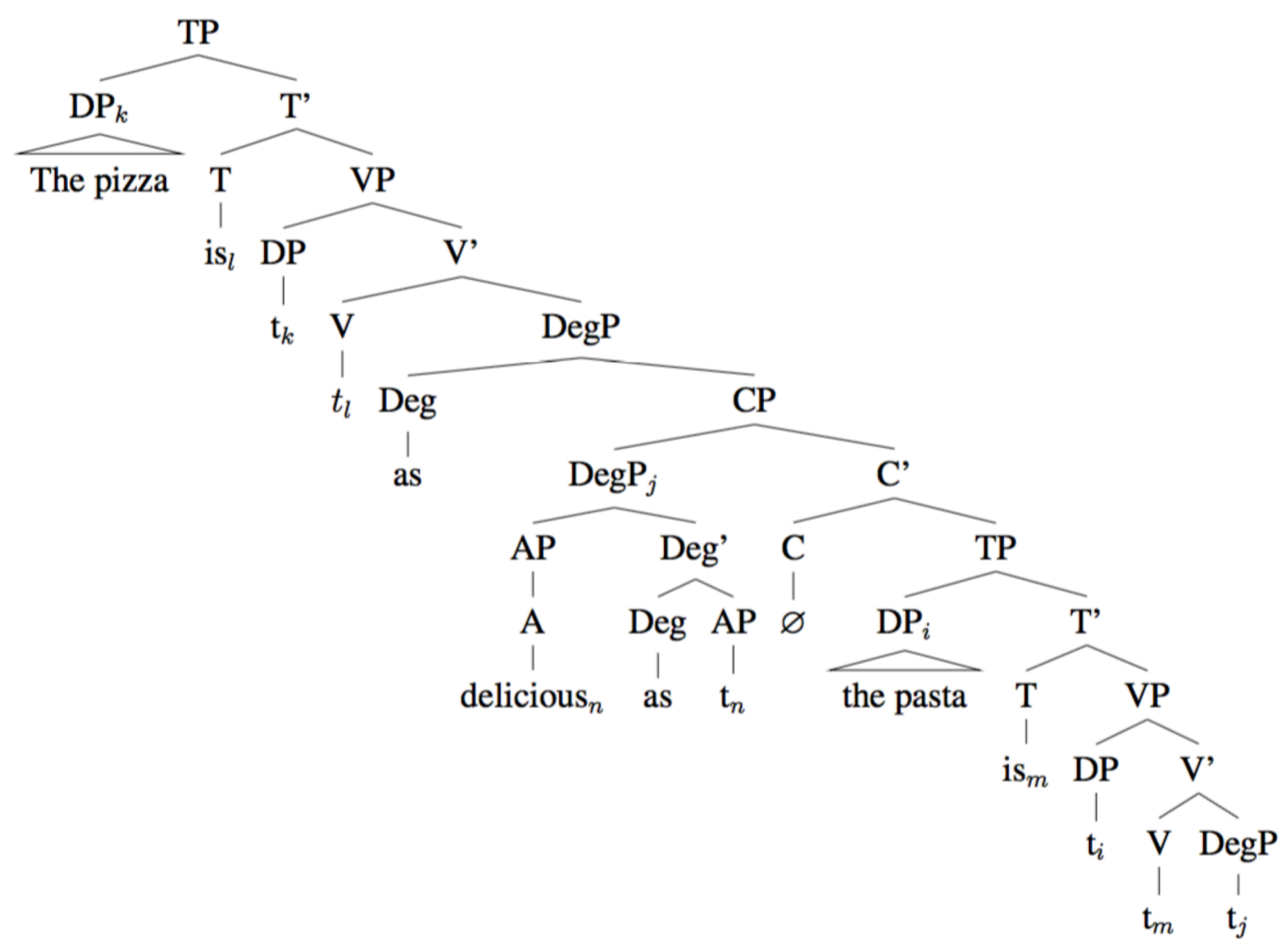

One final piece of evidence that comparatives derive from the movement of degree elements comes from analyzing comparative subdeletion as in the following examples:

(19) John is as honest as the day is long.

(20) Mary is as happy as Mount Everest is tall.

Such sentences are further evidence for the fact that comparative relative clauses operate over degrees because degree is the only thing in common between honest and long and between happy and tall in (19) and (20) respectively; it cannot be the adjectives that are related because the matrix clause and the comparative clause contain different adjectives.

6. Idiom-based evidence for the raising analysis of comparatives. Like interrogatives, canonical relative clauses exhibit pied-piping; indeed, as Bianchi (2002) discusses, relative clauses are more liberal than interrogatives in terms of what entities can be pied-piped. The DegPs that raise to become the heads of relative clauses under the promotion analysis can also trigger pied-piping as illustrated in (21) and (22):

(21) John is not as nice [a person as $]_{i}$ Mary is $t_{i}$.

(22) John is not as talented [a teacher as $]_{i}$ Mary is $t_{i}$.

In these cases, rather than as acting alone as the wh-phrase, the entire phrase a person as or $a$ teacher as is the wh-phrase.

Vergnaud (1974) uses both binding theory and idiom chunks to justify the promotion analysis of relative clauses, but in section 3, only binding theory evidence was offered to justify analyzing comparatives as relative clauses. There are some idioms, such as short shrift and in high 
dudgeon, which obligatorily contain certain adjectives, but comparatives constructed by moving these adjectives result in sentences that are at best marginally grammatical. However, piedpiping can be used to generate some evidence from idiom chunks as in the following sentences:

(23) ? I have never experienced as powerful a punch as this movie packed.

(24) ? I have never seen as straight a beeline as John made for the cookies.

The sense of punch used in (23) only occurs when punch has been selected for by pack. (23) therefore suggests that at the least a punch was moved, and following the analysis of such phrases as instances of pied-piping, this implies that powerful also has moved. Similarly, beeline only occurs in the idiom make a beeline, which suggests that straight a beeline moved upward from the position following made in (24). Both of these cases therefore bolster the evidence from section 3 arguing for comparatives as relative clauses created by promotion.

Section 1 discussed how comparatives can compare the degrees of DPs as well as adjectives and adverbs. It would thus make sense to say that the Deg head of a DegP can select a DP, in which case the example of pied-piping seen in (21) would be structured as follows:

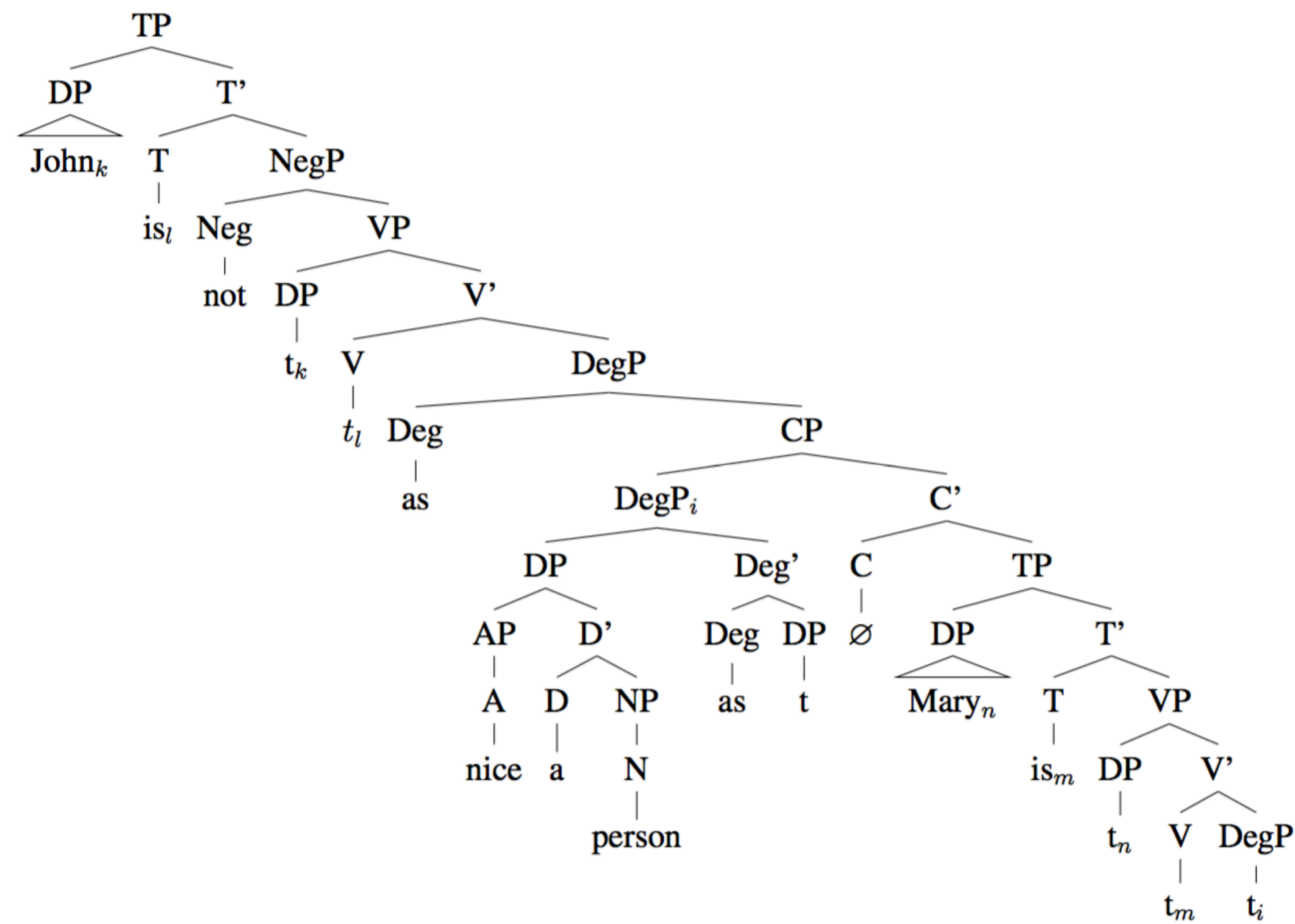

7. As as a $\boldsymbol{w h}$-word. The treatment of phrases beginning with as as relative clauses is further supported by some evidence based on the distribution of as. Specifically, some dialects of English allow (or at least have allowed) the usage of as in place of that or who to introduce a relative clause. Examples of such usage are in (26), which is taken from Vanity Fair by William Makepeace Thackeray, and in (27), which is taken from The Mill on the Floss by George Eliot: 
(26) And Simpson, the man as was very noisy and drunk indeed, says nothing shall go out of the house until his wages is paid up.

"What am I to write?" said Tom, with gloomy submission.

"Write as your father, Edward Tulliver, took service under John Wakem, the man as had helped to ruin him..."

Thus, although comparatives cannot occur with that as other relative clauses can, it is reasonable to treat as as a complementizer or wh-word introducing the comparative clause.

8. Conclusion. Comparatives, such as He's not half as courageous as his father was, can in fact be treated as relative clauses. Like relative clauses, they are formed through $w h$-movement; where relative clause formation involves promotion of a DP, comparative formation involves degree and adjective raising. This analysis is facilitated by treating adjective phrases as truly being degree phrases headed by the degree of the adjective.

This analysis removes the need to treat comparatives and relative clauses differently and resolves the adjective movement discrepancy between questions and relative clauses. Therefore, it strengthens the status of $w h$-movement as a unifying operation across many different syntactic constructions.

\section{References.}

Abney, Steven Paul. 1987. The English Noun Phrase in its Sentential Aspect. Doctoral dissertation, MIT.

Bianchi, Valentina. 2002. Headed relative clauses in generative syntax - Parts I and II. Glot International 6: 1-8, 197-204.

Bresnan, Joan W. 1973. Syntax of the comparative clause construction in English. Linguistic Inquiry 4.3: 275-343.

Chomsky, Noam. 1977. On wh movement. Formal Syntax, 71-132. New York: Academic Press.

Kayne, Richard. 1994. The Antisymmetry of Syntax. Linguistic Inquiry Monograph Twenty-Five: 85-92. MIT Press.

Kennedy, Christopher. 1999. Projecting the adjective: The syntax and semantics of gradability and comparison. New York and London: Routledge.

Lechner, Winfried. 1998. Phrasal comparatives and DP-structure. Proceedings of NELS, Vol. 1. Amherst, MA: Graduate Linguistic Student Association, UMass Amherst.

Ross, John Robert. 1967. Constraints on variables in syntax. Doctoral dissertation, MIT. Vergnaud, Jean-Roger. 1974. French Relative Clauses. Doctoral dissertation, MIT. 